\title{
1. User generated law: re-constructing intellectual property law in a knowledge society
}

\section{Thomas Riis}

\section{INTRODUCTION}

The exact elements of what constitutes a 'knowledge society' are still disputed. Yet the underlying notion that modern society and not least the modern economy are essentially based on the production and dissemination of knowledge is not contested. The most widely shared understanding deems that a knowledge society is characterized by a high absorptive capacity; by the possession of structures and cultures that facilitate dissemination and sharing of knowledge; and by the inclusion of learning communities which emphasize innovation. A knowledge society's main tool is information exchange via information and communication technologies. Information is a knowledge-generating tool; it is not knowledge itself. Knowledge relates to the practical use of information and involves a human experience. ${ }^{1}$ Our contemporary knowledge society faces the crucial challenges of establishing structures and arrangements that support the creation of legitimate and productive knowledge and ensuring access to knowledge. Legal infrastructure is essential in shaping such structures and arrangements. Technological and economic development have been the major forces in creating a knowledge society (which by nature is a dynamic society) whereas the legal infrastructure which regulates behaviour in this knowledge society has not developed correspondingly.

Traditionally, law has been construed as being authoritatively determined by national legislative directives. In cases of uncertainty concerning the contents of these directives, national Supreme Courts have been envisaged as the source of legal certainty. This construction is ill-suited to meeting the needs of a knowledge society. In a knowledge society, law

\footnotetext{
1 See the UNESCO World Report, Towards Knowledge Societies (2006).
} 
must be capable of managing more complex and flexible relationships and there is often a high degree of heterogeneity in the demands for legal solutions. Additional characteristics of a knowledge society that challenge the traditional mode of legal regulation include the increase in cross-border activities - knowledge recognizes no borders - and the speed of technological and commercial development which rapidly makes previously well-functioning legal solutions obsolete or inadequate. ${ }^{2}$

A critique of the traditional regime of law production is not new; but such criticism has differed in terms of its angles and content. Normative statements on the quality of legal regulation presuppose a choice of value foundations. At the most general level, all sorts of acceptable legal models must arguably include a notion of justice and a regard for fundamental rights. At the instrumental level, a choice must be made on what policy objectives legal regulation is supposed to promote. In this latter instance, legal regulation is supposed to promote dynamic efficiency, innovation and growth in a knowledge society which is basically an objective of economic welfare.

Kobayashi and Ribstein note that scholars have often recognized the potential shortcomings of State-enacted laws due to the fact that public lawmakers are susceptible to powerful interest groups and have weak incentives to produce socially valuable legal innovations, in part because they share little of the public benefits of producing laws. ${ }^{3}$ Kobayashi and Ribstein's focus is on various public choice problems in law production. This book adopts a different approach by examining how law production is determined by the intrinsic characteristics and needs of the actors in a knowledge society, thus shaping new framework conditions for the production of law by means of feedback loops. The book is a study in the development and elaboration of law and it is based on the premise that law which accommodates the needs of knowledge is characterized by:

1. flexible norms (reflecting both the complexity and rapid pace of development);

2. a cross-border scope (reflecting the global dimension);

2 E.g. Gillian K. Hadfield, 'Producing Law for Innovation', in Kauffman Task Force on Law, Innovation and Growth, Rules for Growth (2011) pp. 36 et seq.

Bruce H. Kobayashi and Larry E. Ribstein, 'Law as Product and Byproduct' (2013) 9 Journal of Law, Economics \& Policy 521, p. 522. See also e.g. Gillian K. Hadfield, 'Producing Law for Innovation', in Kauffman Task Force on Law, Innovation and Growth, Rules for Growth (2011), pp. 23 et seq. 
3. the capacity to be industry-specific and subject-specific (reflecting the heterogeneity of the demands for legal solutions).

Seen from this perspective, law can no longer be perceived as a closed, primarily autonomous system directed by national legislators and national courts. ${ }^{4}$ This book examines how private regulatory models evolve either as new layers of law based on State-enacted law, or as sui generis legal systems. By examining concrete cases of private regulatory models we shall determine what conditions drive the formation of these alternative forms of legal regulation which can be subsumed under the concept of user generated law.

\section{PRIVATE REGULATORY MODELS AND THE FRAGMENTATION OF LAW}

Various actors often have divergent demands for legal solutions in a knowledge society context. In order to meet those demands they construct private regulatory models. However, a variety of private regulatory models, each governing a specific activity with a limited scope, leads to fragmentation of the law. Thomas Schultz addresses a key instance of this concerning law in cyberspace which is an essential part of a modern knowledge society. Schultz describes the State as having a decreased capacity to code power in this domain, and adds that: 'Cyberspace is carved up into different spheres of normativity, some of which are connected only remotely to other normative systems' ${ }^{5}$

Private regulatory models have a long history and lex mercatoria has a prominent place in legal studies of such models. Lex mercatoria refers to the system of rules detached from national law and national courts used by merchants in the Middle Ages to govern commercial transactions in Europe. It was affirmed as a coherent system of transnational rules enacted by applying commercial customs and enforced by threat of

4 For a related perspective, see Jan M. Smits, 'Private Law 2.0: On the Role of Private Actors in a Post-National Society' (November 30, 2010), Hague Institute for the Internationalisation of Law and Eleven International Publishing, 2011; Maastricht Faculty of Law, available at http://ssrn.com/abstract=1779042 (accessed January 19, 2016).

5 Thomas Schultz, 'Private Legal Systems: What Cyberspace Might Teach Legal Theorists' (2007) 10 Yale Journal of Law \& Technology 151, p. 193. 
boycott and expulsion ${ }^{6}$ and it was thus claimed to be a privately produced, privately adjudicated, and privately enforced body of law.

The traditional notion maintaining that lex mercatoria was actually a systematic law (standardized across Europe, synonymous with commercial law, unaffected by governments and sovereignty) has now been disputed. ${ }^{7}$ Yet the notion does indicate a need spanning many centuries for privately produced law based on the idea that merchants were a better source of rules for governing commercial practices than local rulers. The comparison between lex mercatoria and regulatory models in the information society has been made by Trakman in connection with the law of domain names:

The ICANN and WIPO policies, principles, and rules include precepts attributed to the Law Merchant ... The ICANN and its main service provider, the WIPO, seek to promote a cosmopolitan and uniform system of rules that transcends local rules and nation states. ... Many of the characteristics of the medieval Law Merchant are apparent in domain-name jurisprudence. In particular, domain-name disputes are resolved efficiently and at a comparatively low cost. ${ }^{8}$

The law of domain names comprises legal rules adopted by ICANN and relies on established trademark law principles; and as such it differs from lex mercatoria where the transnational rules were created by applying commercial customs. ${ }^{9}$ However, other parts of privately produced regulatory models in our existent knowledge society can be said to have been composed by applying commercial customs (e.g. the collective management of patent rights, and to a certain extent the collective management of copyrights).

6 Cf. Albrecht Cordes, 'The Search for a Medieval Lex Mercatoria' (2003) Oxford University Comparative Law Forum, 5, available at http://ouclf. iuscomp.org/articles/cordes.shtml\#fn14sym, p. 17 (accessed January 19, 2016).

7 E.g. Christopher R. Drahozal, 'Contracting out of National Law: An Empirical Look at the New Law Merchant' (2004-2005) 80 Notre Dame Law Review 523, p. 527; and Ralf Michaels, 'The Mirage of Non-State Governance' (2010) Utah Law Review 31, pp. 37 et seq.

8 Leon E. Trakman, 'From the Medieval Law Merchant to E-Merchant Law' (2003) 53 University of Toronto Law Journal 265, pp. 287 et seq.

9 Leon E. Trakman, 'From the Medieval Law Merchant to E-Merchant Law' (2003) 53 University of Toronto Law Journal 265, pp. 289 et seq. 


\section{USER INNOVATION}

Schultz's description of the fragmentation of law is arguably pertinent to law in a knowledge society in general, but it does not explain how the law evolves. For that purpose, and with strong inspiration from Eric von Hippel's theory on user innovation, we shall develop a new perspective on law which we will call user generated law. ${ }^{10}$ The theory concerning user innovation relates to the development of products and services and it explains why innovative products and services are developed by users under certain conditions while manufacturers create development under other conditions.

The ensuing attempt to apply a new perspective on law is based on the premise that the development of law in a knowledge society and the development of products and services have many common features. The 'users' in law are the persons subjected to the law. In cases where it is not optimal for these persons to rely on State-enacted law they may opt out and establish a private form of legal regulation, primarily by contractual means (the legal innovation). The creation of products and services and the creation of regulatory models are not identical processes. First, the possibilities of opting out of State-enacted law are in some areas of law (chiefly in public law) very restricted due to mandatory rules. In comparison, most innovative products and services can be created and marketed without significant legal constraints. In order to deal with that challenge the concept of 'autonomy spaces' is incorporated into the notion of user generated law. ${ }^{11}$ Second, the concept of 'user' in regard to law may appear somewhat obscure. In principle, all persons are subjected to all parts of the law. However, far from all persons will have an interest in opting out of a certain part of the law; such an interest will only arise if the person is appreciably affected by the law in question. Thus, the users in user generated law are not simply the persons subjected to the law but rather those who are affected by it.

Another aspect of the user concept needs to be clarified. A person who has an interest in opting out of State-enacted law and creates a legal innovation does not necessarily do it by herself but will often commission a team of lawyers and other consultants to do the job. Even though the team contributes to the creation of the legal innovation (and quite possibly the innovation would not have come into existence if it were not

10 Eric von Hippel, The Sources of Innovation (Oxford University Press, 1988); Eric von Hippel, Democratizing Innovation (MIT Press, 2005).

11 On 'autonomy spaces', see para. 4.1 below. 
for the team) the person who initiates and organizes the process that leads to a legal innovation is the 'user' for the purpose of user generated law.

When law is produced in a new way we need a new model in order to construe the process. Regarding products and services, von Hippel claims that new sources of innovation demand new management tools as well as a new organization, ${ }^{12}$ and in the same vein it can be claimed that the prevalence of user generated law will demand new framework conditions for the production of law.

\subsection{Heterogeneous Demands}

It follows from the theory on user innovation that user innovations are developed as a result of heterogeneous and small scale demands. Users' needs for products and services are highly heterogeneous in many fields. Economies in the production process spur manufacturers to employ a strategy of developing products that are designed to meet the needs of one large market segment or a few large market segments. The resulting supply of products is characterized by a few different versions of the product that are supposed to meet the needs of all the users. In other words, manufacturers adopt a strategy of 'few sizes fit all'. Since users' needs are heterogeneous, this strategy will leave many users dissatisfied with the commercial products on offer. When a user does not find what they want on the market they have no other choice but to modify existing products or to develop entirely new products - namely, to innovate in order to meet the user's individual needs which the majority of consumers do not share. ${ }^{13}$

\subsection{Expectation of Benefits (Profits)}

Heterogeneous demand is not in itself a sufficient reason why user innovation will occur. The theory on user innovation is based on the traditional economic rationale maintaining that actors act if they think that it will be beneficial for them to do so - that is, if they expect an attractive return. Hence, a user will innovate if they foresee an in-house benefit from doing so and typically (and in contrast to the manufacturer)

12 Eric von Hippel, The Sources of Innovation (Oxford University Press, 1988), p. 9.

13 Eric von Hippel, The Sources of Innovation (Oxford University Press, 1988), p. 7; and Eric von Hippel, Democratizing Innovation (MIT Press, 2005), p. 5. 
the user does not consider whether other users have similar needs. The manufacturer also considers the benefits, but it is typically a precondition for a manufacturer that many users have similar needs for the innovative product to be profitable. ${ }^{14}$ Whether an innovation is made by a manufacturer or a user depends on the relative benefits of the innovations for the two parties. A user innovation may be made if it implies small or no benefits for the manufacturer, which is often the case where the innovative product or service is easily copied by other manufacturers (for instance due to the lack of practical and legal means of protecting the innovation). ${ }^{15}$ This scenario suggests that users obtain benefits in ways which differ from manufacturers and thus that the incentive structures are different. It has been shown that in general patent protection is less necessary and more costly for user innovations than for innovations made by manufacturers. ${ }^{16}$

\subsection{Asymmetric Information}

Knowing about needs in the market place is crucial in manufacturing. However, information on users' needs is not equally distributed. Normally the manufacturer has inadequate information on users' needs. Users are the first to know about their own needs and the information on users' needs is not easily distributed to manufacturers. Eric von Hippel uses the term 'sticky information' and it creates a case of asymmetric information. Since existing information asymmetries cannot be erased easily or cheaply, each innovator will tend to develop innovations that draw on the sticky information they already have, because it is the cheapest course of action. ${ }^{17}$ This is another reason why many users do not find what they want in the market and choose to innovate.

\subsection{The Role of Lead Users}

In envisaging final determinants for user innovation, von Hippel has identified a certain category of actors that he calls 'lead users'. Studies show that many users develop and modify products for their own use but

14 Eric von Hippel, The Sources of Innovation (Oxford University Press, 1988), p. 7.

15 Eric von Hippel, The Sources of Innovation (Oxford University Press, 1988), p. 63.

16 Katherine J. Strandburg, 'Users as Innovators: Implications for Patent Doctrine' (2008) 79 University of Colorado Law Review 467.

17 Eric von Hippel, Democratizing Innovation (MIT Press, 2005), p. 70. 
innovation is concentrated among lead users. Lead users share two characteristics. First, they are ahead of the majority of users in their populations with respect to an important market trend and so are currently experiencing needs that will later be experienced by many users in that market. Consequently, lead users understand emerging user needs and markets better than manufacturers and ordinary users. Second, lead users anticipate relatively large benefits from obtaining a solution to their needs and may consequently innovate. ${ }^{18}$

In conclusion, four determinants for the emergence of user innovations can be identified: (1) heterogeneous demands; (2) expectation of benefits (profits); (3) asymmetric information between users and manufacturers; and (4) the existence of lead users.

After a user innovation has emerged a phase may follow in which the innovation is diffused through networked media and a community may form around the innovation. Finally, as the last phase, a manufacturer may adopt the innovation to develop and market a commercial version.

\section{USER GENERATED LAW}

In the following sections the structural similarities between product and service innovations and legal innovations will be investigated. It is anticipated that the circumstances and the actors involved in the development of legal innovations will to a high degree resemble the development of product and service innovations. If the two production processes can sustain a comparison in this way, the insights of von Hippel's theory can provide a better understanding of how user generated law develops.

The theory on user innovation has certain policy implications since von Hippel claims that in general user innovations are undervalued and that the obstacles to user innovations are not properly understood. As a consequence, it would be beneficial to society at large to address these obstacles and provide the best conditions for the promotion of user innovation. If user generated law entails the same societal benefits as user innovations, the model can contribute to the creation of a better legal process, and the theory can be used to identify the best legal institutional conditions for the promotion of user generated law.

A model of user generated law in a knowledge society relates to a variety of legal disciplines. In this work the concrete cases of private regulatory models are taken from the area of intellectual property law but

18 Eric von Hippel, Democratizing Innovation (MIT Press, 2005), pp. 5, 22. 
the methodological framework could be extended to other parts of law. Intellectual property law is essential to the legal infrastructure of a knowledge society. The underlying rationale of intellectual property law can be construed as a balancing mechanism that on the one hand provides economic incentives for the creation of new knowledge, information, and innovation, while on the other hand ensuring access for others to this new knowledge, information, and innovation. This is a balance between the interests of creators and the interests of users.

Due to factors such as the time $\operatorname{lag}^{19}$ and inflexibility involved in the traditional model of legal regulation (statutory law and case law) this model and the notion of intellectual property law as a balancing mechanism have been challenged in today's knowledge society and a number of new non-legislative regulatory models have emerged. It is common to many of these regulatory models that the authoritatively determined regulation does not work as intended and private arrangements redefine the legal position and change the balance between the opposing interests.

The theory on user innovation suggests the following determinants of user innovation:

1. Heterogeneous demands.

2. Expectation of benefits (profits).

3. Asymmetric information between users and manufacturers.

4. User innovation is most likely to occur if there are lead users.

For the purposes of the user generated law perspective we shall study whether the emergence of private regulatory models within intellectual property rights depends on the same four determinants.

After studying the emergence of the private regulatory models we shall examine whether the models follow the same phases as those ascribed to user innovations:

Phase 1: Emergence

Phase 2: Diffusion

Phase 3: Adoption

19 See e.g. Paul M. Romer, 'Process, Responsibility, and Myron's Law', in Olivier J. Blanchard, David Romer, Michael Spence, and Joseph E. Stiglitz (eds), In the Wake of the Crisis: Leading Economists Reassess Economic Policy (MIT Press, 2012), pp. 112 et seq. 
'Emergence' refers to a situation where a regulatory model (the legal innovation) is created and used by the parties affected by it. 'Diffusion' simply means that the legal innovation is copied and used by other parties, and 'adoption' implies that the legal innovation is acknowledged by the legislator or other producers of State-enacted law as a regulatory model that works well.

\subsection{Autonomy Spaces}

Different applicable rule-sets in a knowledge society are formed by two major forces: the pressure of public policy protection as enunciated by the State and commercial efficiency as pursued by private actors. ${ }^{20}$ Public policy protection is motivated by ideological as well as efficiency concerns. Public efficiency concerns include supporting private transactions, balancing information asymmetries, sustaining the production of public goods, and redressing externalities. ${ }^{21}$ The same two major forces influence the development of new products and services. However, in regard to products and services the pressure of economic efficiency is by far the most dominant factor.

In law the situation is somewhat different because in some parts of State-enacted law public policy considerations are so strong that private actors only have very limited freedom to establish private regulatory models. In other parts of State-enacted law public policy considerations play a minor role which gives a large degree of freedom to establish private regulatory models. The State-enacted law defines a space within which persons may act autonomously which will hereafter be termed the autonomy space. In parts of State-enacted law where public policy protection plays a minor role, the autonomy space is wide and in parts of State-enacted law where public policy protection is dominant the autonomy space is narrow. In some regulated fields there are not really any autonomy spaces because the persons subjected to the law must simply comply. For example, all persons have to comply with the applicable, valid tax law rules.

Even in cases where persons cannot substitute a private regulatory model for an existent law there may be possibilities for the persons to opt out of the law by changing behaviour or institutional nature. For

20 In the same vein, see Thomas Schultz, 'Carving up the Internet: Jurisdiction, Legal Orders, and the Private/Public International Law Interface' (2008) 19(4) The European Journal of International Law 799, p. 805.

21 Cf. Anthony Ogus, Regulation. Legal Form and Economic Theory (Clarendon Press, 1994), pp. 29 et seq. 
example, a production company that wants to avoid the high corporation tax in the country where it is established can move the company to another country with a lower corporate tax rate. ${ }^{22}$ However, the concept of user generated law developed here shall be understood as privately produced law developed in autonomy spaces. User generated law emerges in these autonomy spaces. Outside the autonomy spaces private parties cannot enter into a valid mutual agreement or other regulatory model stating that another set of legal rules ought to apply to them.

In reality, the borders of autonomy spaces are diffuse. Parties are not actually prevented from acting outside autonomy spaces; but if they do they may be met with legal sanctions or remedies. Rational parties are expected to act if the benefits of the act exceed the costs. If the legal sanctions and remedies for not respecting the autonomy space are severe the likelihood that the parties will comply with normative law is relatively high. However, in certain fields (for instance where violations are difficult to detect or where enforcement is problematic) there may be no real legal effect of not complying with normative law. In those cases the de facto autonomy space may be much broader than the de jure autonomy space. The claim that actions are determined by the balancing of benefits and costs may be modified by the internalization of social norms. In the literature on behavioural theory and social norms it is noted that due to the existence of social norms people do not always appear to behave in a rational way and that behaviour may therefore deviate from economic predictions. ${ }^{23}$ It has been demonstrated how obedience to the law may stem from other reasons than the threat of sanctions, namely that law violations have reputational consequences. ${ }^{24}$ Accordingly, the discrepancy between de facto and de jure autonomy spaces may not be as large as predicted by mainstream economic reasoning.

Policy implications arise from the diffuse borders of autonomy spaces as well as from the fact that the de facto autonomy spaces may be larger than the de jure autonomy spaces. Provided that user generated law

22 On the substitution of law in other ways than those contemplated here see, inter alia, Erin A. O'Hara and Larry E. Ribstein, The Law Market (Oxford University Press, 2009); Roger Van den Bergh, 'Towards an Institutional Legal Framework for Regulatory Competition in Europe' (2000) 53 Kyklos 435; and Norbert Reich, 'Competition between Legal Orders: A New Paradigm of EC Law?' (1992) 29 Common Market Law Review 861.

23 E.g. Cass R. Sunstein, 'Social Norms and Social Roles' (1996) 96 Columbia Law Review 903.

24 Tom R. Tyler, Why People Obey the Law (Princeton University Press, 1990). 
(respectful of the relevant public policy concerns) performs better than State-enacted law, the legal framework for user generated law is improved by clarifying the State-enacted law which defines the autonomy spaces and by legal means to enforce the borders of the autonomy spaces.

\section{PHASE 1: EMERGENCE}

Von Hippel's empirical studies find that the functional source of innovation differs strikingly across the several types of product and process innovation he has explored. ${ }^{25}$ This finding is not surprising and the same must be expected in law. User generated law is expected to emerge in some parts of law and not in others and must furthermore be expected to have a larger impact in some parts of the legal system than in others.

User generated law emerges where private actors expect such law to perform better than State-enacted law. Various reasons may potentially give rise to this situation. Gillian K. Hadfield has studied the privatization of commercial law and claims that politicians and bureaucrats do not evaluate and pursue innovations in law in the ways that entrepreneurs do - with the speed, flexibility, resources, and incentives of the market at their disposal. ${ }^{26}$

\subsection{Heterogeneous Demands}

The heterogeneous legal demands existent in today's knowledge society are reflected in Thomas Schultz's notion concerning law in cyberspace, according to which the internet will be increasingly carved up into distinct spheres or virtual spaces governed by different rule-sets. ${ }^{27}$ It is reasonable to presume that demands for law are highly heterogeneous due to the multitude of different business models, user communities, transactions, and so forth which continuously come into existence in this knowledge economy and due to the diverse interests involved in these phenomena.

25 Eric von Hippel, The Sources of Innovation (Oxford University Press, 1988), p. 28.

26 Gillian K. Hadfield, 'Privatizing Commercial Law' (Spring 2001) Regulation Magazine 41.

27 Thomas Schultz, 'Carving up the Internet: Jurisdiction, Legal Orders, and the Private/Public International Law Interface' (2008) 19(4) The European Journal of International Law 799, p. 805, see also pp. 828 et seq. 
In the development of new products and services it is characteristically assumed that the manufacturer must find a need and fill it by executing new product development stages, provided that the demand for the new product is estimated to be large enough. In law it is different. When it comes to State-enacted law that creates autonomy spaces, such law is primarily based on public policy considerations which again are determined by the needs of society at large rather than the needs of the persons affected by the law. Often the purpose of State-enacted law that creates autonomy spaces is to prevent the persons affected by the law from doing what they would prefer to do. In such cases it is not very useful to speak about heterogeneous demands for law even though such demands do exist - for instance in regard to adequate standards for environmental protection and the scope of prohibitions on additives in foodstuffs - because it is not crucial for the legislator to satisfy the different demands and preferences of the groups of persons affected by the law. The legislator will simply adopt the law that is presumed to be best for society at large and create the legal framework that applies equally to all persons irrespective of their demands and preferences.

In conclusion, there are probably heterogeneous demands for all kinds of law; but since such claims are not necessarily valid or relevant in regard to public law that creates autonomy spaces the notion of user generated law developed here cannot explain this area of law. ${ }^{28}$

State-enacted law that creates autonomy spaces adds a further complication to the emergence of legal innovations because such law may be the result of two different processes. A proactive process is used when the legislator adopts law that defines the autonomy space before an actual legal need has emerged. ${ }^{29}$ The reason for using a proactive process is that

28 The delimitation of law that creates autonomy spaces as opposed to other parts of law bears some resemblance to the distinction made by Anthony Ogus between 'facilitative law', which is law that provides mechanisms for ensuring mutually desired outcomes, and 'interventionist law', which protects defined interests and/or supersedes voluntary transactions; cf. Anthony Ogus, 'Competition between National Legal Systems. A Contribution for Economic Analysis to Comparative Law' (1999) 48 The International and Comparative Law Quarterly 405, pp. 410 et seq.

29 The mirror image of the proactive legislative process has been termed 'preemptive self-regulation', which refers to the situation where the relevant industries use some form of self-regulation to react to concern from the public and policy-makers expressed through such channels as the threat of increased regulation. See Jason M. Solomon, 'New Governance, Preemptive SelfRegulation, and the Blurring of Boundaries in Regulatory Theory and Practice' (2010) Wisconsin Law Review 591. 
a future need for legal regulation is anticipated and the legislator determines the width of the autonomy space on the basis of efficiency and public policy considerations. In a reactive process the legislator has left a legal vacuum and user generated law develops in this vacuum spontaneously. ${ }^{30}$ After the development of the user generated law two things can happen. Either the user generated law is perceived as being in conflict with the needs of society at large and the legislator decides to narrow down the autonomy space, or the user generated law is found to be in conformity with the needs of broader society and the State decides not to intervene in this private practice or institutionalizes it into State-enacted law. In the two latter situations the user generated law is said to be fully adopted. ${ }^{31}$

\subsection{Expectation of Benefits}

According to mainstream economic theory innovation is seen as having a positive impact on social welfare because innovation enables new and better products, cheaper products, or indeed both. Innovation thus increases product variety. As a starting point great product variety is assumed to be desirable because, compared to a situation with lesser product variety, it enables most consumers to acquire products which better satisfy their preferences. However, new products only come at a cost. The producer of a new product must pay fixed costs associated with the development and marketing of a new product. In order to recoup the fixed cost the producer must demand a higher price for the new product variety and the more product varieties the smaller market segment for each variety. Accordingly, the producer can only benefit from small scale economies in production. ${ }^{32}$

Seen from the point of view of consumers, the lowest product price is offered when there is only one product variety in the market. The individual consumer will be willing to pay a higher price for a new product variety that more closely corresponds to the preferences of the consumer. Since consumers have different preferences they also have different preferred product varieties. Each new product variety requires

30 This situation may reflect the observation made by Gillian K. Hadfield, 'Privatizing Commercial Law' (Spring 2001) Regulation Magazine 40, p. 45, according to which one of the striking features of the history of private legal regimes is that they appear only to emerge where there is an absence of public law.

See para. 7 below.

32 Eric von Hippel, Democratizing Innovation (MIT Press, 2005), p. 110. 
development costs and if too many product varieties are developed the aggregated development costs exceed the aggregated added value for the consumers and there is a case of over-provisioning. If, on the other hand, the added value for the consumers of a new product variety exceeds the costs of developing the variety there is a case of under-provisioning.

To sum up, variety is a good thing for users and for society; but only to a certain point. Beyond that point the costs of variety outweigh the benefits. The unresolved issue in this context is whether the same basic trade-off between variety and cost also applies to privately produced regulatory models.

First, it is reasonable to assume that there are substantial fixed costs involved in the creation of a new private regulatory model. Irrespective of the type of model, it always requires human resources (often of a highly specialized and costly nature) to create a new regulatory model. ${ }^{33}$ In addition, it is necessary to distinguish between regulatory models that do not require an institutional set-up (such as pure contractual arrangements) and models that do (such as copyright collecting societies which require an organization to collect remuneration). Obviously, the latter types of models require additional costs. The mere fact that fixed costs are involved in the development of a new regulatory model suggests that there is an upper limit to the optimal degree of variety in private regulatory models. Following the market economic rationale the entity that creates a new regulatory model must have an expectation that the fixed costs will be recouped. Von Hippel talks about innovators (either user or manufacturer) who expect a temporary profit as a precondition for innovating. The same can be said about user generated law but the notion needs to be expanded.

Normally, regulatory models are not sold in the same way as products. Instead, they generate value by being used. ${ }^{34}$ For instance, a group of

33 See, however, Robert G. Bone, 'Decentralizing the Lawmaking Function: Private Lawmaking Markets and Intellectual Property Rights in Law' (2014) 38 International Review of Law \& Economics 132, p. 140: 'While it is ultimately an empirical question, ordinary experience suggests that creativity in law usually involves only modest upfront investment compared to other types of creativity. There are exceptions, of course, but modest investment seems likely in most cases.'

34 User generated protective regimes have emerged even in fields where some intellectual protection is available. In one study it is suggested that the main reason for this is that the State-enacted intellectual property system is too rigid and too costly to use. See David Fagundes, 'Norms-Based Regulation of Intellectual Property: The Case of Roller Derby Pseudonyms' (2012) 90 Texas Law Review 1093, p. 1093. 
companies may create a contractual model that reduces the commercial risks involved in a certain type of transaction. The contractual model generates value for the companies by reducing risks since risks represent costs. The more the contractual model is used, the more value it generates. In addition, it must be assumed that in some cases innovators can generate benefits of a non-economic nature that are sufficiently high to spur innovation. That will be the case if the incentive for the innovator is not an expected economic income but an increase in the innovator's reputation with her peers or in a community. The more the innovation is used the more the innovator's reputation is increased. Therefore, irrespective of the sort of benefits user generated law may create, it can be stated that a new regulatory model will only be created if it is expected to be sufficiently used (extensively or intensively). ${ }^{35}$

Some intuitive insights and anecdotal evidence can be gained from the open content licences provided by Creative Commons. Creative Commons offers standard open content licence agreements that right-holders can choose to use when they want to license their work. A right-holder is free to write her own licence agreement that perfectly conforms to her needs and such a licence is no less binding than a Creative Commons licence. Nevertheless, a large and increasing number of right-holders decide to use the Creative Commons licence instead of making a licence agreement themselves despite the fact that the Creative Commons licence may not be the optimal licence for many of the right-holders. For these right-holders the additional value of making their own licence contract does not exceed the cost of making such a contract (working hours, cost of legal advice, and so forth). Therefore, it is rational for them to use Creative Commons.

Creative Commons combines standard agreements with flexibility by offering six standard agreements to choose between. When the rightholders have a choice between more standard contracts, they get more precisely what they want. But why does Creative Commons not offer the

35 According to von Hippel it is problematic if potential innovators do not measure benefits in commensurable ways: 'However, the model will not be practicable in fields where all potential innovators do not measure the rents they expect in commensurable ways. This is so simply because the hypothesis that underlies the model requires that one compare levels of expected rents across functional groups in order to predict the functional source of innovation. And this is only possible in fields where all classes of potential innovators with a significant potential interest in an innovation use commensurable measures.' Cf. Eric von Hippel, The Sources of Innovation (Oxford University Press, 1988), p. 71 . 
greater variety represented by 20 or 50 standard contracts? In that case each right-holder would get a standard contract closer to the rightholder's optimal contract. Arguably, the reasoning from product variety is not convincing in this respect because Creative Commons is an NGO not governed by profit motives and the costs of developing new contract versions are presumably not decisive. The cost of variety must be found among the right-holders who are the users of the contracts. A possible explanation could be that a large variety of contracts complicates the choice. The presence of many choices implies that the right-holder must use time considering each choice and perhaps seek legal advice to choose the best contract. The hypothetical situation where the right-holder could choose between an indefinite number of standard contracts equates cost-wise to the situation where the right-holder decides to write an individual licence contract.

The Creative Commons example above points to another issue where the creation of legal innovations may diverge from the creation of product and service innovations. In the theory on user innovation the person who creates the innovation is supposed to benefit from using or selling the innovation and that is not the case for an NGO such as Creative Commons. It may be argued that Creative Commons benefits from the widespread use of its licences by an increase in the organization's reputation in the community. However, since the organization does not follow the norms of the market it is reasonable to assume that the organization is primarily driven by a sense of altruism and therefore does not act in conformity to mainstream economic reasoning. ${ }^{36}$ This may be an important issue when the theory on user innovations is applied to legal innovations since NGOs such as Creative Commons may turn out to be a major source of legal innovations.

36 A similar explanation is given by David Fagundes regarding individual persons who have invested considerable time in creating an IP-like name registration system for the benefit of a sports league, cf. David Fagundes, 'Norms-Based Regulation of Intellectual Property: The Case of Roller Derby Pseudonyms' (2012) 90 Texas Law Review 1093, pp. 1138 et seq. See, however, the critical comments of Robert Ellickson, 'How Norm Entrepreneurs and Membership Associations Contribute to Private Ordering: A Response to Fagundes' (2012) 90 Texas Law Review 247; and the reply, David Fagundes, 'The Varieties of Motivation and the Problem of Supply: A Reply to Professor Ellickson' (2012) 90 Texas Law Review 311. 


\subsection{Asymmetric Information}

In the development of new products and services manufacturers do not know emerging users' needs as well as users and, in particular, lead users do. ${ }^{37}$ The same can be said for some areas of law; yet for other areas of law it is different. ${ }^{38}$ State-enacted law that creates autonomy spaces is primarily based on public policy considerations and thus information on users' needs is not particularly relevant. When an autonomy space is narrowed down by law the purpose is to prevent the persons affected by the law from acting in certain ways when such actions create harmful effects on third parties (externalities) or violate moral norms in the given society. For that purpose, the State/legislator does not have to know about the exact needs of the persons affected by the law; the decisive information relates to the effects of the actions on third parties. ${ }^{39}$ It has already been stated that law that defines autonomy spaces cannot be explained by the concept of user generated law. Hence, possible information asymmetries are only relevant concerning law that can emerge within autonomy spaces. Since information on legal needs within autonomy spaces is not equally distributed among the State/legislator and the parties affected by the law there is a case of asymmetric information.

One issue is that the State/legislator has inadequate information on users' legal needs that emerge within autonomy spaces; another issue is that such needs are presumably very diverse because they are by definition heterogeneous demands for law. Satisfying such heterogeneous demands is a very complex task and normally the users must be assumed to be able to deal with the complexities in a more efficient way. The State/legislator must aim to take into consideration the needs and preferences of all persons in a given society and adopt the best possible legal model which applies to all persons in that society. By comparison an individual user has the much simpler task of establishing a regulatory model that optimizes the individual user's needs and preferences.

37 On lead users, see para. 5.4 below.

38 Cf. Erin A. O'Hara and Larry E. Ribstein, The Law Market (Oxford University Press, 2009), pp. 14 et seq.; and Jan M. Smits, 'Private Law 2.0: On the Role of Private Actors in a Post-National Society' (November 30, 2010). Hague Institute for the Internationalisation of Law and Eleven International Publishing, 2011; Maastricht Faculty of Law, available at http://ssrn.com/ abstract $=1779042$, p. 17 (accessed January 19, 2016).

39 The needs of the persons affected by the law are not wholly irrelevant. If it turns out that a planned restriction on an autonomy space will have significant harmful effect on these persons, the restriction can be reconsidered. 
Asymmetric information in relation to the creation of new regulatory models may also be present when one party (the legislator) has an abundance of information but is not able to distinguish between more and less relevant information. This may be an important factor in law due to lobbying in the legislative process. Lobbyists provide information with a specific view on the issues and the result may be an information overload that obscures rather than clarifies.

Legislators' lack of information may explain the emergence of a number of private protective regimes that complement protection under State-enacted intellectual property law. Emmanuelle Fauchart and Eric von Hippel have studied the emergence and functioning of a norm-based intellectual property system among French chefs which provides protection of recipes. They found the existence of a social norm that prohibits exact copying of recipes. According to another norm among the chefs, a chef who asks for and is given proprietary information by a colleague would not pass that information on to others without permission. Additionally, a third norm implied the right to be acknowledged as the author of a recipe one has created. The study found that violations of the norms were punished by shaming, loss of status within the community, and reduced future access to valuable community resources such as information. ${ }^{40}$ This norm-based intellectual property system studied by Fauchart and von Hippel is not a legal model; they have defined their research object as a pure, norms-based intellectual property (IP) system that is based entirely upon social norms, possessing a functionality similar to that offered by law-based systems. Thus, it is user generated regulation but not user generated law. It does, however, illustrate the emergence of private regulation in a context where the absence of any State-enacted IP system for chefs' creations is explained by asymmetric information. The State does not know about the needs of such a system and the resulting benefits stemming from it.

Similar norm-based systems have also been shown to exist among stand-up comedians regarding the protection of jokes, ${ }^{41}$ and among magicians regarding the protection of magic tricks. In the latter case, the IP system is supported by codes of conduct adopted by the magicians'

40 Emmanuelle Fauchart and Eric von Hippel, 'Norms-Based Intellectual Property Systems: The Case of French Chefs' (January 2006) MIT Sloan Working Paper 4576-06.

41 Dotan Oliar and Chris Sprigman, 'There's no Free Laugh (Anymore): The Emergence of Intellectual Property Norms in Stand-Up Comedy' (2008) 94 Virginia Law Review 1787. 
organizations and a violation of the norms may lead to expulsion from the organization. ${ }^{42}$

In the same vein, a number of non-optimal and possibly superfluous State-enacted regulatory models can be explained by asymmetric information. The United States was the first jurisdiction in which specific rules for the protection of semiconductor products were adopted by the Semiconductor Chip Protection Act (SCPA) of 1984. The Act establishes a complicated protective regime based on registration of sui generis rights to so-called mask works fixed in semiconductor chip products. Foreign mask works are granted protection on the basis of a reciprocity principle; so in order to ensure protection of EU citizens' mask works in the United States, the EU adopted the Semiconductor Directive ${ }^{43}$ that is based on registration as well and also has many other similarities with the SCPA. However, neither the SCPA nor the Semiconductor Directive seems to have any practical impact in the affected industries. Arguably, the first reason for this is that the object of protection (the design of the topography) does not correspond to the need of the producers whose commercial interests are closely connected to the function of the semiconductor. A second reason is that registration of a new topography in all countries possibly involves too much expenditure of money and human resources. Instead, producers of semiconductor products have found more efficient means of protecting their investments in the technological development. ${ }^{44}$

Another example of a different nature is the multilingual EU open source standard contract European Union Public Licence (EUPL) ${ }^{45}$ that

42 Jacob Loshin, 'Secrets Revealed: Protecting Magicians' Intellectual Property without Law', in Christine A. Corcos (ed.), Law and Magic. A Collection of Essays (Carolina Academic Press, 2010) pp. 123-41.

See also the emergence of a private intellectual property system in the US fashion industry, cf. Kal Raustiala and Christopher Sprigman, 'The Piracy Paradox: Innovation and Intellectual Property in Fashion Design'(2006) 92 Virginia Law Review 1687, pp. 1695 et seq.; and Robert P. Merges, 'From Medieval Guilds to Open Source Software: Informal Norms, Appropriability Institutions, and Innovation' (November 13, 2004), available at http://ssrn.com/ abstract=661543 or http://dx.doi.org/10.2139/ssrn.661543, p. 19 (accessed February 3,2016$)$.

43 Council Directive 87/54/EEC of 16 December 1986 on the legal protection of topographies of semiconductor products.

44 See e.g. Gunnar W. G. Karnell, 'Protection of Layout Designs (Topographies) of Integrated Circuits - R.I.P.?' (2001) IIC 648.

45 See the Commission's website at https://joinup.ec.europa.eu/software/ page/eupl. 
was launched by the European Commission ${ }^{46}$ in January 2007. The standard contract is used by various EU Member States in public governed software programs, but has not had any substantial impact on the open source sector in general. A plausible explanation for the meagre success of the EUPL is simply that users do not have a need for it. More established and widespread open source standard licences have positive reputational effects that make it costly for software producers to switch to a new standard contract such as the EUPL.

\subsection{The Role of Lead Users}

According to von Hippel, lead users are users whose present strong needs will become general in the market place months or years in the future. Lead users play an essential role in a fast-moving world. Conversely, in a relatively slow-moving world, new versions of a product do not differ radically from their immediate predecessors. A new product is thus reasonably familiar and a typical user (and not necessarily a lead user) will be representative of the users' needs. In a fast-moving world typical users' real world experience is often rendered obsolete by the time a new product is developed and the manufacturer needs the experience of lead users who are in advance of product development. ${ }^{47}$

When a lead user modifies a product (i.e. makes an innovation) the market for the innovation is typically too small for a manufacturer to commercialize it. However, the lead user is at the leading edge of a market trend and when the market catches up it may be profitable for manufacturers to commercialize the innovation. In this way, successful innovations start up as user innovations and are subsequently adopted by manufacturers who commercialize them. As part of this process lead users can provide very useful information to manufacturers which they would not otherwise gather. ${ }^{48}$ Manufacturers need not explore such users' needs very accurately. They need to ascertain how the innovative product is designed by lead users, not why it is designed in this way.

The lead user demonstrates a higher level of innovative activities because the lead user is the party who expects to gain the most from a new product or service.

46 Strictly speaking, the Commission is not the EU legislator but it is an inherent part of the EU legislative process.

47 Eric von Hippel, 'Lead Users: A Source of Novel Product Concepts' (1986) 32(7) Management Science 791, p. 796.

48 Eric von Hippel, Democratizing Innovation (MIT Press, 2005), p. 108. 
The prevalence of lead users in law is not as evident. An example of lead users in law may be the French authors who formed the first copyright collecting society, the French organization Société des Auteurs et Compositeurs Dramatiques (SACD) in 1777. Similar societies were later formed in other countries and in 1926 the performing rights societies formed the association International Confederation of Authors and Composers Societies (CISAC) to manage their common interests. The CISAC created, among other things, a model contract for reciprocal representation that set the standard for collective management of copyright in Europe until it was contested for being anti-competitive by the European Commission in a 2008 decision. ${ }^{49}$

When looking at the provision of standard contracts on open source and open content the entities that are ahead of the majority of users with respect to an important market trend are not users themselves in the sense that they are not developing the open licence contracts with the primary purpose of using the contract for their own activities and they are not selling the contracts to users. For instance, Free Software Foundation, which created the open source model contract GNU General Public License, and Creative Commons, which created the Creative Commons Licenses are non-profit organizations that have developed the model contracts in question for the use of others and their major mission is to disseminate the use of the contracts as widely as possible. What motivates the apparently altruistic work in such organizations falls outside the scope of this book. However, in this context the term 'lead user' is misleading. For the development of a model on user generated law the term 'lead actor' is a more exact term that shall, in addition to organizations, comprise inter alia communities and intermediaries who set the scene and are perceived as directly or indirectly representing user interests. Contrary to the lead user notion in the theory on user innovation, often lead actors are not motivated by an expectation of obtaining benefits from the creation of a legal innovation (cf. para. 5.2 above).

\section{PHASE 2: DIFFUSION}

The three phases in user generated law (emergence, diffusion, and adoption) indicate that the strongest societal impact arises from the user generated law which passes through the final phase and is adopted. Legal

49 Commission Decision of 16 July 2008 case COMP/C-2/38.698 - CISAC, [2008] OJ C 323/12. 
innovations may be diffused through networked media in the same way as innovative products and services; and a community may be formed around the legal innovation. Numerous communities of this nature exist: for instance the non-profit organization ICANN in domain name law, collecting societies in copyright law, and patent pools in patent law.

In regard to new products and services the extent of diffusion is assumed to be closely related to the costs of copying, but diffusion may also be affected by other factors such as reputational effects and network effects. Some innovative products may be costly to copy; yet more importantly innovations may be protected by intellectual property rights which more or less effectively preclude others from copying it. Notably, though, legal protection of innovations is more often applied by manufacturers than by users. According to von Hippel, empirical research shows that new and modified products developed by users often do diffuse more widely than innovations made by manufacturers. The reason for the wide diffusion of user innovations is that user-innovators themselves often voluntarily publicly reveal what they have developed for all to examine, imitate, or modify without any payment to the innovator. ${ }^{50}$ Since user-innovators often do not seek to maximize the economic return from others using the innovation, this suggests that user-innovators obtain benefits in other ways.

If a legal innovation becomes sufficiently diffused it will possibly obtain a positive reputational effect that reduces the uncertainties for new users and therefore be diffused even more. Here, too, the Creative Commons licences provide an example. Creative Commons licences are used widely and the extensive use may reassure new users that unexpected serious legal risks are not involved and that the licences in general seem to work well.

Pursuing the Creative Commons example and focusing on the copyleft provision $^{51}$ (in Creative Commons terminology: the 'share alike' provision) it is possible that there is even a network effect involved that increases diffusion. A network effect exists when one user of a product has a positive effect on the value of that product to other people. When a network effect is present, the value of a product increases with the number of other persons using the product. The copyleft provision imposes a duty on the licensee who remixes, transforms, or builds upon the licensed work to distribute the derivative work under the same licence

\footnotetext{
50 Eric von Hippel, Democratizing Innovation (MIT Press, 2005), p. 77.

51 A copyleft provision is also included in the GNU General Public License for instance.
} 
as the original. The purpose of the copyleft provision is to ensure that subsequent users of a derivative work are offered the same freedoms to use as the author of the derivative work was offered in regard to the original work. If the author of the derivative work uses other contractual means than the corresponding Creative Commons licence there may be doubt as to whether copyleft compliance has been met. The corresponding Creative Commons licence is definitely compatible with the copyleft provision and the use of that licence facilitates subsequent licensing.

There are indications that when it comes to mass uses of privately produced regulatory models, reputational effects play a decisive role in the diffusion of the model. The name of the model functions like a trademark and may develop into a strong brand that further extends the dissemination of the model. Creative Commons and GNU General Public License are well-known names which not only inform prospective users that the licences work well and without unexpected legal risks, they have also developed into strong brands with values that are independent of the underlying legal standard contracts. Thus, some persons are using Creative Commons and GNU General Public License because it has symbolic value to them. In this way, the use of such contracts with well-known names is a means to signal to rest of the world that the user is associated with the communities surrounding the contracts.

\section{PHASE 3: ADOPTION}

According to von Hippel, a manufacturer may adopt the innovation in order to develop and market a commercial version as the last phase in the process. This is not a foregone conclusion because users can bypass manufacturers altogether.

The relevant legal innovation can be said to be 'adopted' in two situations. First, if the legislator and other producers of State-enacted law acknowledge the legal innovation by deciding that it works well and that there are no grounds for legal corrections of the model, then the innovation is adopted. Second, the legal innovation is adopted if it is incorporated into State-enacted law. For instance, the innovation may be adopted as statutory rules or the courts may apply the legal innovation as the default rule. Alternatively, the legal innovation may be incorporated into State-enacted law by means of customary law.

In reality it may prove difficult to determine whether privately created legal innovations have been adopted if the legislator has not acted in relation to the legal innovation. The lack of legislative intervention in 
relation to a legal innovation is not equivalent to the State's approval of the legal innovation because the legislator must be allowed a reasonable period of time to evaluate whether a legal innovation is working well or needs to be corrected. In the same vein, a reasonable period of time for evaluation is also needed for a legal innovation that previously worked well but, due to changes in the surrounding conditions, is not necessarily working well anymore.

The act of 'adoption' is not an either/or decision. The legal innovation may be fully accepted (adopted) and it may be fully rejected (nonadopted); yet presumably the most prevalent situations are those where the central part of the legal innovation is found to work well but at the same time there are minor legal corrections required (namely, an adjustment of the autonomy spaces).

\section{THE INTERNATIONAL DIMENSION}

Internationalization is a dimension that is not addressed in the theory of user innovation but is essential to conceptions of law in a knowledge society. Internationalization of cyber law has been highlighted by Thomas Schultz, arising from the simple fact that the internet is international by nature and is concerned with global economies. Schultz's characteristic of the internet seems pertinent to a knowledge society in general:

our general understanding of the Internet forms one of the paradigms which underlie the general view of deterritorialization, transnationalism, state decline, and the replacement of national pyramids of normativity by global networks of spread-out normativity. ${ }^{52}$

Such an understanding is in conflict with the traditional process of law production characterized by a national legislator adopting statutes and national courts that interpret the statutes. Privately produced regulatory models have the potential to be truly global and as such to be independent of any nation states even though they rely on national courts for enforcement. ${ }^{53}$

52 Thomas Schultz, 'Carving up the Internet: Jurisdiction, Legal Orders, and the Private/Public International Law Interface' (2008) 19(4) The European Journal of International Law 799, p. 801.

53 Thomas Schultz, 'Private Legal Systems: What Cyberspace Might Teach Legal Theorists' (2007) 10 Yale Journal of Law \& Technology 151, p. 154. See 
The enforcement dimension of law creates links of different strengths to national legal systems. National courts must respect national mandatory provisions and differing legal cultures may affect legal interpretation. Hence (to offer just one example) it is possible that an alleged breach of the GNU General Public License could be litigated in courts of two different countries and produce opposite results. In principle, it must be assumed that a legal innovation enforced by the ordinary courts will have a relatively strong link to national legal systems compared to a legal innovation enforced by arbitration.

\section{PROSPECTS FOR A MODEL ON USER GENERATED LAW}

This book (and the underlying research project) developed from an observation that much law in our knowledge society is a matter of self-regulation; and in order to understand such law, the pertinent focus for legal study should shift to these legal phenomena rather than statutory intellectual property rights which have dominated the scholarly discussion on the legal infrastructure of today's knowledge society.

In this introductory chapter a preliminary attempt has been made to adapt the theory of user innovation to law, which is one way to explain and construe law in a knowledge society. Prima facie, there appear to be many similarities in the creation of innovative products and services vis-à-vis legal innovations. However, on a few points the theory on user innovation does not seem to reflect the legal world.

In the following chapters various examples of privately produced regulatory models will be studied. A primary purpose of the chapters is to examine whether a model of user generated law is a useful framework for analysing legal innovations created by their users. If that is the case, it should be possible to identify the drivers that create these forms of private regulatory models. The chapters will also examine the characteristics of the regulatory models that can be subsumed under the notion of user generated law in order to determine the impact of user generated law on the legal infrastructure of a knowledge society.

Law is different from products and services. Most importantly, law includes a number of inherent values (such as the rule of law founded upon consistency and predictability, or legitimacy and protection of

also Gunther Teubner, 'Breaking Frames: The Global Interplay of Legal and Social Systems' (1997) 45 American Journal of Comparative Law 149, p. 157. 
minority interests), which are not relevant for the creation of innovative products and services. For instance, the producers of user generated law do not necessarily represent all persons affected by the law, which may create a legal situation where one group of people is shown preference on account of another group. If third persons are actually harmed by user generated law an externality has been created. Even in the absence of externalities, user generated law may create biases that are found to be unbalanced. Such externalities and biases may, in conformity to the prevailing political preferences, give rise to legal intervention by adjusting the autonomy spaces. This continuous interaction between legal innovations and the legal framework is not reflected in the theory on user innovation, which therefore needs to be developed and enriched when adapted to the legal world.

The interaction between legal innovations and the legal framework (the scope of the autonomy spaces) raises the question on how State-enacted law may be amended to facilitate the emergence and maintenance of efficient forms of user generated law. If the model of user generated law outlined here is adequate and useful in explaining and construing our knowledge society's privately produced regulatory models, it may also prove useful in providing policy prescriptions for the content of Stateenacted laws that create the autonomy spaces. 